\title{
Impact of personality on vengeance and forgiveness in young adults
}

\begin{abstract}
This study aimed to identify personality traits that affect vengeful and forgiving behavior among young adults. Big Five Personality Inventory, Vengeance Scale and Trait Forgiveness Scale were administered to 159 male and female students selected by using convenient sampling technique to have a base-line data for the study. Overall, agreeableness trait predicted forgiveness. Vengeance showed significant negative correlation with agreeableness, conscientiousness and openness. Whereas Independent T-test indicated that personality traits plays crucial role in determining vengeful and forgiving behaviors in contrast to gender in young adults.
\end{abstract}

Volume 2 Issue 5 - 2015

\author{
Marium Javaid Bajwa, Ruhi Khalid \\ Marium Javaid Bajwa, Beaconhouse National University, Lahore, \\ Pakistan
}

Correspondence: Beaconhouse National University, Lahore, Pakistan,Tel 92 3238829697, Email marium.bajwaa@gmail.com

Received: December 02, 2014 | Published: April 22, 2015

Keywords: personality, traits, vengeance, forgiveness

\section{Introduction}

Our modern era is obsessed with a belief in vengeance. Media is endlessly bombarding society with depictions of supposedly "sweet" vengeance. Entertainment channels in Pakistan are spreading desperation and despair in society by focusing on bitter realities and sufferings of life and promoting vengeance as the last resort to end those sufferings. People do not seem tended to forgive others and are more likely choose to ignore forgiveness. Apathy is replacing empathy and people are becoming indifferent to the sufferings of others. Vengeance has been the central theme of many TV dramas like "Kadurat" Darmiyan" Intekam" "Mera Sultan" getting aired on Pakistani entertainment channels, as they do not present the reality but somehow are a reflection and representation of a reality in a twisted way and are influencing people's behaviors, perceptions and their personalities. ${ }^{1}$ The desire for vengeance and capability to forgive are universal human psychological endowments. ${ }^{2}$ In terms of personality correlates, vengefulness and forgiveness has been shown to be associated with Big Five components of personality. ${ }^{3-5}$ McCullough et al., ${ }^{6}$ found that vengeance has positive correlation with neuroticism and negative correlation with agreeableness unlike forgiveness which is positively correlated with agreeableness and negatively with vengeance. ${ }^{7-9}$ Skarlicki et al., ${ }^{10}$ discovered that in comparison to people who are stable and agreeable, neurotic and disagreeable individuals are more likely to retaliate against perceived acts of injustice and find it difficult to forget about negative experiences. ${ }^{11}$ Studies indicate that forgivingness and extraversion has a positive association as forgivingness is characterized as a proclivity to get over the negative emotions of unforgivingness with positive emotions. ${ }^{12}$ According to a hypothesis by Exline, ${ }^{13}$ individuals might choose forgiveness because forgiveness is an act that is in sync with their moral code. In such decision- based forgiveness, forgiveness is possibly motivated by conscientiousness rather than by empathy and positive affect. ${ }^{13-15}$ In many studies, forgiveness unlike vengeance has been linked with positive emotions such as trust, love, kindness, sympathy, selflessness, as openness trait categorized attributes adventurous interests, imaginative, insightful, tender-mindedness and sympathy, forgiveness and openness showed positive association with each other. ${ }^{7,16,17}$

Several theories included trait dimension related to affection, kindness, empathy, selflessness are traits that are features of forgiveness, such as Big Five model of personality includes trait Agreeableness; ${ }^{3}$ intimacy motivation from McAdams's theory. ${ }^{18}$ These theories also include a domain related with self-auspice or the sensing of threats, such traits might be considered as a feature of vengeful behavior and include domains like neuroticism in the Big Five model and power motivation in McAdams's theory. ${ }^{18}$ Reiss et al., ${ }^{19}$ identified 16 root factors to fundamental motivation, of which vengeance (defined as the desire to get even or win) is one. Applying sensitivity theory to the concept of fundamental motivations and media comportments, Reiss $\&$ Wiltz $^{20}$ suggest that truculent people watch bellicose programs because such shows arouse feelings of vindication, which, in turn, gratifies their rudimentary desire for vengeance.

Literature on vengeance indicates that vengeance might alter with gender, age and power difference. ${ }^{21,22}$ Stuckless \& Goranson ${ }^{23}$ suggested that men have higher tendencies than women toward both vengeance and trait anger and men are more likely to punish opponents who had behaved unfairly and are more inclined toward aggressive behavior than women, particularly when it physically harms another person. ${ }^{24}$

Despite the increasing trend of taking revenge and lacking forgiveness in Pakistani society and significance of the topic from psychological context it still lacks importance among Pakistani researchers. By recognizing the relationship of personality traits with revenge and forgiveness, we will be able to educate people about its functions and promote and raise awareness about positive behaviors like forgiveness, empathy and altruism. Since most of the studies were conducted in Europe on this topic, the fundamental purpose of the study is to see how well data from Pakistan support the western literature on personality, vengeance and forgiveness. Secondly by carrying this research we will be able to find out how people who seek revenge and forgiveness differ on personality traits and which personality trait i.e. openness, extraversion, neuroticism, agreeableness and conscientiousness determine vengeance and forgiveness.

\section{Hypotheses}

1. Neuroticism trait and vengeance has statistically significant negative relationship with forgiveness.

2. Neuroticism trait is a statistically significant predictor of vengeance in individuals. 
3. Personality traits openness, extraversion, conscientiousness and agreeableness of Big-five inventory are statistically significant predictors of forgiveness.

4. Vengeance has a statistically negative relationship between personality traits openness, extraversion, conscientiousness and agreeableness of Big-five inventory.

5. Men compared to women, have significantly higher scores on vengefulness, but lower on measures of forgiveness.

\section{Method}

\section{Sample}

The sample consisted of 159 participants, males $(M=73.2, S D=17)$ and females $(M=32.4 S D=6.2)$ university students between the age range of 21 and 29 from the University of Management and Technology. Participants were enrolled in different programs including, Psychology, Mass Media Communication, Architecture, Textile Designing and Business programs.

\section{Measures}

Big Five Inventory ${ }^{25}$ : BFI (Big Five Inventory) consisted of 44 item personality inventory, used to measure five dimensions of personality, i.e. Extraversion, Agreeableness, Conscientiousness, Neuroticism and Openness. Participants responded to statements on a 5- point likert scale; strongly disagree $=1$ to strongly agree $=5$. Each subscale consists of 8-10 items. Authors reported internal consistencies of .75 to .88 for each subscale. ${ }^{25}$

Vengeance Scale ${ }^{23}$ : Vengeance Scale consisted of 20 items was used to measure the attitude of participants towards Vengeance. Participants responded to statements on a 7- point likert scale; strongly disagree $=1$ to strongly agree $=7$. High scores indicated greater level of vengeance. Stuckless \& Goranson, ${ }^{23}$ the authors of the scale reported a Cronbach's alpha of .92.

Trait Forgivingness Scale ${ }^{7}$ : The 10 item version of Trait Forgivingness Scale, measure of dispositional forgivingness was used. Participants responded to statements on a 5-point likert scale; strongly disagree $=$ 1 to strongly agree $=5$, with a Cronbach's alpha of $\alpha=.80$. High score indicated greater level of forgiveness.

\section{Procedure}

An authority letter from the institute of Psychology, Beaconhouse National University, Lahore explaining the nature of the research and request for the permission of data collection was taken to seek permission from head of the University.

A total of $\mathrm{N}=159$ participants, age ranged 21-29 were selected by using a convenient sampling technique. Data were collected in spring semester 2014 at the university campus during university hours Participants were approached in their classes with the permission of relevant teachers. They were briefed about the research and requested to participate in this study. Consent was taken from the participants after having explained them the aim and nature of research. Demographic information regarding participants' age, course of studies and level of semester in which they were enrolled at the university was taken. After that Trait Forgiveness Scale, Vengeance Scale and Big Five Inventory were given to participants in a sequence. It took participants 35-40minutes to complete their responses.

\section{Results}

On the basis of entire sample of $(N=159)$, an account of the overall descriptive statistics is given below (Table 1). The relationship between vengeance and forgiveness was significantly negative, as theoretically expected. It means individuals who are vengeful were less vulnerable to forgive others. Vengeance has strongly negative relation with agreeableness, conscientiousness and openness, i.e. vengeful individuals were more prone to disagree with others and vice versa. Relationship of forgiveness with agreeableness was highly positive and negative with neuroticism: forgiving individuals were more likely to agree with others. The correlation among variables made psychological sense and were theoretically in line. This shows that subjects participated honestly in the research and data was discrete, non- random and credible.

Table I Mean, Standard Deviation and Correlation Matrix of the Study Variables (N=159)

\begin{tabular}{|c|c|c|c|c|c|c|c|c|}
\hline & Variables & M (SD) & A & C & $\mathbf{N}$ & O & $\mathbf{F}$ & V \\
\hline I & $\mathrm{E}$ & 26.1 (5.3) & -0.03 & $.18^{*}$ & $-.16 *$ & $.27 * * *$ & 0.07 & -0.08 \\
\hline 2 & $A$ & $32.7(4.8)$ & & $.31 * * *$ & -0.03 & $.41 * * *$ & $.34 * * *$ & $-.47 * * *$ \\
\hline 4 & $N$ & $24.0(5.6)$ & & & & 0.01 & $-.19 * *$ & 0.02 \\
\hline 5 & O & $35.2(5.1)$ & & & & & 0.13 & $-.28 * * *$ \\
\hline 6 & $F$ & $31.7(6.3)$ & & & & & & $-.48 * * *$ \\
\hline
\end{tabular}

Note: E: Extraversion, A:Agreeableness, C: Conscientiousness, N: Neuroticism, O: Openness, F: Forgiveness, V:Vengeance

$*_{p}<0.05, * * p<0.01$, *** $p<0.001$

Table 2 Hierarchical Regression Analysis for Neuroticism as a Predictor of Vengeance

\begin{tabular}{llll}
\hline \multicolumn{4}{l}{ Vengeance } \\
\hline Variables & B & SE & $\boldsymbol{\beta}$ \\
\hline Constant & 68.7 & 5.8 & \\
Neuroticism & 0.08 & 0.23 & 0.02 \\
R & & 0.02 & \\
F & & 0.12 & \\
\hline
\end{tabular}

$* p<0.05, N=159$ 
Table 3 Hierarchical Regression Analysis for Openness, Conscientiousness, Agreeableness and Extraversion as Predictors of Forgiveness

\begin{tabular}{|c|c|c|c|c|c|}
\hline \multicolumn{6}{|c|}{ Forgiveness } \\
\hline Variables & $\mathbf{R}$ & $\mathbf{F}$ & B & SE & $\beta$ \\
\hline Constant & 0.01 & & 26.1 & 3.4 & \\
\hline Openness & & 2.7 & 0.16 & 0.09 & 0.13 \\
\hline Constant & 0.03 & & 30.5 & 2.8 & \\
\hline \multicolumn{2}{|c|}{ Conscientiousness } & 0.19 & 0.04 & 0.09 & 0.03 \\
\hline Constant & 0.11 & & 17 & 3.2 & \\
\hline Agreeablen & & $21.0^{*}$ & 0.44 & 0.09 & 0.34 \\
\hline Constant & 0.07 & & 29.3 & 2.5 & \\
\hline Extraversio & & 0.99 & 0.09 & 0.09 & 0.07 \\
\hline
\end{tabular}

$* p<0.05, N=159$

Table 4 Vengeance and Forgiveness Scores of Males and Females $(\mathrm{N}=159)$

\begin{tabular}{lllll}
\hline \multicolumn{1}{c}{ Males $(\mathbf{n}=\mathbf{8 0})$} & Females $(\mathbf{n}=\mathbf{7 9})$ & & \\
\hline Variables & $\mathbf{M}(\mathrm{SD})$ & $\mathbf{M}(\mathrm{SD})$ & $\mathbf{t}$ & $\mathbf{p}$ \\
\hline Vengeance & $73.2(17.0)$ & $68.3(16.5)$ & 1.8 & 0.07 \\
Forgiveness & $32.4(6.2)$ & $31.1(6.3)$ & 1.8 & 0.2 \\
\hline
\end{tabular}

H1: Neuroticism trait and vengeance has statistically significant negative relationship with forgiveness.

Table 1 shows that forgiveness has a high and inverse correlation with neuroticism trait and vengeance $(r=-.19, p<.01),(r=-.48, p<$ $.001)$. This supported the above hypothesis.

H2: Vengeance has a statistically negative relationship between personality traits openness, extraversion, conscientiousness and agreeableness of Big-5 model.

Table 1 shows that vengeance has a strong and inverse correlation with conscientiousness trait agreeableness trait and openness trait $(r=$ $-.47, p<.001),(r=-.27, p<.001),(r=-.28, p<.001)$. There was an inverse correlation between extraversion trait and vengeance but it was not significant $(r=-.47, p>.05)$. Thus this partially supported the above hypothesis.

H3: Neuroticism trait is a statistically significant predictor of vengeance in individuals.

Taking leads from the findings of Table 1, hierarchical regression analysis was run to estimate the affect of neuroticism trait on vengeance. Result shows Neuroticism $(\beta=.02, p>.05)$ not as a predictor of vengeance. This means that trait of neuroticism do not predicts vengeance $(\mathrm{F}=.127, p>.05)$. The overall model showed that only $6 \%$ of vengeance can be explained through targeted variable (Table 2).

H4: Personality traits Openness, Extraversion, Conscientiousness and Agreeableness of Big-five inventory are statistically significant predictors of forgiveness.

In Table 3, result shows Openness trait $(\beta=.13, p>.05)$ not as a predictor of forgiveness. This means that trait of openness do not predicts forgiveness $(\mathrm{F}=2.7, p>.05)$. The overall model showed that only $13 \%$ of forgiveness can be explained through targeted variable. Conscientiousness trait $(\beta=.03, p>.05)$ was also found as not a predictor of forgiveness. This means that trait of conscientiousness do not predicts forgiveness $(\mathrm{F}=.19, p>.05)$. The overall model showed that only $5 \%$ of forgiveness can be explained through targeted variable. Result shows agreeableness $(\beta=.34, p<.001)$ as a predictor of forgiveness. This means that trait of agreeableness do predicts forgiveness $\left(\mathrm{F}=21.0^{*}, p<.001\right)$. The overall model showed that $34 \%$ of forgiveness can be explained through targeted variable
(Table 3). Result shows extraversion ( $\beta=.07, p>.05$ ) not as a predictor of forgiveness. This means that trait of extraversion do not predicts forgiveness $(\mathrm{F}=.99, p>.05)$. The overall model showed that $6 \%$ of forgiveness can be explained through targeted variable (Table 3).

H5: Men compared to women, have significantly higher scores on vengefulness, but lower on measures of forgiveness

An Independent Sample t-Test showed that there was not a significant difference $(p>.05)$ on vengeance and forgiveness between males and females. Thus this rejected the above hypothesis (Table 4).

\section{Discussion}

Overall relationship among the psychological variables of the study indicated that most of the variables displayed sufficient dispersion of scores indicating that the sample comprised of general group of people rather than selected one. These variables predicted well and yielded meaningful psychological indices of correlation. Interestingly all the variables were interrelated and made psychological sense.

The key finding of the study is that vengeance and forgiveness were negatively correlated $(r=-.48, p<.001)$ in accordance with the study by $\mathrm{Hope}^{2}$ who found that vengeance and forgiveness are two different behavioral adaptations, a person who seeks vengeance cannot forgive and is less vulnerable to forgiveness.

Vengeance showed strong and inverse correlation with agreeableness trait $(r=-.47, p<.001)$. This finding is consistent with that of McCullough, ${ }^{6}$ who found vengefulness and Agreeableness to be negatively associated with each other. It means that vengeful people are tend to disagree with others more. Vengeance showed strong and inverse correlation between conscientiousness trait $(r=-$ $.27, p<.001)$ which is consistent the finding of McCullough ${ }^{6}$, who found vengeance as negatively associated with conscientiousness. As conscientiousness includes attributes such as having general choice and will, ${ }^{26}$ vengefulness will be more decision based despite of negative effect. McCullough et al. ${ }^{6}$ found negative relationship of vengeance with openness which supports the finding that vengeance has a strong and inverse correlation with openness trait $(r=-.28, p<$ $.001)$ and make logical sense as openness trait refers to openness to experience, imagination, attributes like having wide interests, insightful, tender-mindedness and being sympathetic. ${ }^{26}$ Extraversion envelops more specific attributes as talkative, enthusiastic, energetic, 
outgoing and assertiveness. Several studies shows that positive traits influence more forgiveness as compared to vengeance, ${ }^{7,27}$ which supports the finding that vengeance has inverse correlation between extroversion but it was not significant $(r=-.47, p>.05)$. Hence it partially supported the finding as it gave the direction of the variables. Various studies found neurotic individuals are more likely to experience negative effect, as they have tendency to ruminate which results in difficulty to forget about negative experiences. ${ }^{11}$ Moreover, they are sensitive to negative experiences and as a result are easily angered and offended. ${ }^{28,29}$ This combination of qualities may trigger neurotics for vengeance. McCullough et al. ${ }^{6}$ found out that vengefulness has positive association with Neuroticism. Results contradicts the finding of this study as neuroticism $(\beta=.02, p>.05)$ is not a predictor of vengeance. This means that trait of neuroticism do not predicts vengeance $(\mathrm{F}=.127, p>.05)$. The overall model showed that only $6 \%$ of vengeance can be explained through targeted variable. Though the correlation between neuroticism and vengeance Table 2 showed a positive relationship but it was not significant.

Forgiveness showed high and inverse correlation between neuroticism trait $(r=-.19, p<.01)$. This finding is consistent with that of ${ }^{12}$ who found negative association of neuroticism with forgiveness, ${ }^{30,31}$ as neuroticism is a tendency to experience negative effects, such as stress, anxiety, depression and proneness to worry. ${ }^{3}$ McCullough et al., ${ }^{6}$ found forgives positively correlated with agreeableness. This supports the finding that agreeableness $(\beta=$ $.34, p<.001)$ is a predictor of forgiveness. This means that trait of agreeableness predicts forgiveness $\left(\mathrm{F}=21.0^{*}, p<.001\right)$. The overall model showed that $34 \%$ of forgiveness can be explained through targeted variable. Results showed that extraversion $(\beta=.07, p>.05)$ is not a predictor of forgiveness. This means that trait of extraversion do not predicts forgiveness $(\mathrm{F}=.99, p>.05)$. The overall model showed that $6 \%$ of forgiveness can be explained through targeted variable. Though it gave us the positive direction between two variables but it was not significant. Studies indicate that there is a positive association between forgiveness and extraversion as forgiveness is characterized as a tendency to overcome the negative emotions with positive emotions and forgiveness can be or is one mechanism partly responsible for the relative happiness of extroverted people over time. ${ }^{12,32}$ This concludes that forgiveness disposition is positively associated with various traits connected to positive and pro-social affects (agreeableness, empathic concern, perspective taking, and extroversion). Conscientiousness $(\beta=.03, p>.05)$ was found as not a predictor of forgiveness. This means that trait of conscientiousness do not predicts forgiveness $(\mathrm{F}=.19, p>.05)$. The overall model showed that only $5 \%$ of forgiveness can be explained through targeted variable. Exline ${ }^{13}$ found that some individuals choose forgiveness because forgiveness is an act that is in accordance with their moral code and is religiously motivated. ${ }^{13,14,33}$ In such decision- based forgiveness, forgiving behavior is possibly motivated by conscientiousness trait instead of empathy or positive affect. Various studies found forgiveness as positively correlated with openness trait but associations have been weak and unstable across studies. ${ }^{6,7,27,34}$ This finding is consistent with the result that openness $(\beta=.13, p>.05)$ is not a predictor of forgiveness. This means that trait of openness do not always predicts forgiveness $(\mathrm{F}=2.7, p>.05)$. Overall model showed that only $13 \%$ of forgiveness can be explained through targeted variable. Though correlation between two variables showed positive relationship (Table 3).

One main thing that can be concluded from above results especially from non-significant relationship of neuroticism trait and conscientiousness trait with vengeance is that vengefulness and forgiving behavior is likely to be the choice of matter among Pakistani young adults. As most of the Pakistani culture is influenced by the religion and its moral teachings and values, study by Exline, ${ }^{13}$ also supports that individuals choose forgiveness because it is an act that is in sync with people's moral code. Further if a person has any negative traits that doesn't mean he/she has strong vulnerability of acting vengefully.

An Independent Sample t-Test (Table 3) showed that there was not a significant difference $(p>.05)$ on vengeance and forgiveness between males and females. This contradicts with the finding of Stuckless \& Goranson ${ }^{23}$ who suggested that men have higher tendencies than women toward vengeance, trait anger and unforgivingness. As Pakistan has diverse culture and population sample taken in this study was representation of an educational background of young people, as education and age affects a lot one's way of perceiving and thinking through things. Western literature on vengeance also indicated that vengeance might alter with age..$^{21,23}$

\section{Conclusion}

Personality traits i.e. Neuroticism, Extraversion, Agreeableness, Openness, Conscientiousness showed impact on vengeance and forgiveness which sounds psychologically logical. Neuroticism linked positive relationship with vengeance and negative with forgiveness. Whereas traits with positive affect such as Extraversion, Agreeableness, Openness showed negative relationship with vengeance and positive relationship with forgiveness. Though the conscientiousness trait which considered as more decision-making, willful and religiously influenced showed positive relation with forgiveness and strongly negative relationship with vengeance $(p<$ $.001)$. Further, personality traits contributes more in vengeful and forgiving behaviors as compared to gender differences in young adults.

\section{Limitations and suggestions}

Sample of the present study was limited to only one university and student population. However a large pool of participants with different demographics i.e. age, educational background could have been more helpful in providing more insight to the study. Further interviews with the participants could have provided with more detailed result and we would have been able to compare the Pakistani data with western literature on large scale.

\section{Implications of the findings}

The present study bears implication for psychological health and well being of people. To educate people about vengeance and its functions and promote and raise awareness about positive behaviors like forgiveness, sympathy, empathy and altruism. It is recommended that one's attitude of compassion may be fostered to help them practice forgiveness, sympathy, empathy and altruism in daily life. This will also provide insight about human virtues and how to persevere positively amongst such an onslaught of effect of media.

\section{Recommendations for future studies}

i. It would be beneficial to investigate the impact of vengeance and forgiveness in more controlled conditions that would reveal comprehensive results.

ii. Present study can also be extends to different populations, to get more insight regarding the topic.

iii. In light of findings of this study, future researches should explore ways to promote forgiveness. 


\section{Acknowledgments}

None.

\section{Conflicts of interest}

Author declares there are no conflicts of interest.

\section{Funding}

None.

\section{References}

1. Cheema F. Entertainment Media's Role in Spreading Hopelessness. 2013

2. Hope D. The healing paradox of forgiveness. Psychotherapy: Theory, Research, Practice, Training. 1987;24(2): 240-244.

3. John OP. The "Big Five" factor taxonomy: Dimensions of personality in the natural language and in questionnaires. Handbook of personality: Theory and research Guilford Press, New York, USA. 1990. p.66-100.

4. McCrae RR, Costa PT. Personality, coping, and coping effectiveness in an adult sample. Journal of Personality. 1986;54:385-405.

5. McCrae RR, Costa PT. Validation of the five-factor model of personality across instruments and observers. J Pers Soc Psychol. 1987;52(1):81-90.

6. McCullough ME, Bellah CG, Johnson JL, et al. Vengefulness Relationship with forgiveness, rumination, well-being, and the Big Five. Personality and Social Psychology Bulletin . 2001;27(5):601-610.

7. Berry JW, Worthington EL. Forgiveness, relationship quality, stress while imagining relationship events, and physical and mental health. Journal of Counseling Psychology. 2001;48(4):447-455.

8. Mauger PA, Perry JE, Freeman T, et al. The measurement of forgiveness: Preliminary research. Journal of Psychology and Christianity. 1992;11(2):170-180.

9. McCullough ME, Hoyt WT. Transgression-related potential motivational dispositions: Personality substrates of forgiveness and their links to the Big Five. Pers Soc Psychol Bull. 2012;28:1556-1573.

10. Skarlicki DP, Tesluk P, Folger R. Personality as a moderator in the relationship between fairness and retaliation. Acad Manage .1999;42(1): $100-108$.

11. Trapnell PD, Campbell JD. Private self-consciousness and the FiveFactor model of personality: Distinguishing rumination from reflection. J Pers Soc Psychol. 1999;76(2): 284-304.

12. McCullough ME. Forgiveness as human strength: Theory, measurement, and links to well-being. Journal of Social and Clinical Psychology. 2000;19(1):43-55.

13. Exline JJ.When loved ones suffer harm: Protectiveness, loyalty, and other's forgiveness as predictors of one's own anger. Poster session presented at a meeting of the Society for Personality and Social Psychology, Savannah, Georgia, USA. 2002

14. Enright RD, Santos MJ, Al-Mabuk R. The adolescent as forgiver. $J$ Adolesc. 1989;12(1):95-110.

15. McCullough ME, Fincham FD, Tsang JA, et al. Forgiveness, forbearance, and time: The temporal unfolding of transgression-related interpersonal motivations. J Pers Soc Psychol . 2003;84(3):540-557.
16. McCullough ME, Rachal KC, Sandage SJ, et al. Interpersonal forgiving in close relationships: II. Theoretical elaboration and measurement. $J$ Pers Soc Psychol . 1998;75(6):1586-1603.

17. McCullough ME, Worthington EL, Rachal KC. Interpersonal forgiving in close relationships. Journal of Personality and Social Psychology. 1997; 73(2): 321-336.

18. McAdams DP. The person: An introduction to personality psychology (2nd edn) Fort Worth: Harcourt Brace. 1994

19. Reiss S, Haverkamp SM. Towards a Comprehensive Assessment of Fundamental Motivation: Factor Structure of the Reiss Profiles. Psychological Assessment . 1998;10(2):97-106.

20. Reiss S, Wiltz J. Why people watch reality TV. Media Psychology. 2004;6:363-378.

21. Brown RP. Vengeance is mine: Narcissism, vengeance, and the tendency to forgive. Journal of Research in Personality. 2004;38(6):576-584.

22. Stuckless N, Goranson R. A selected bibliography of literature on revenge. Psychol Rep. 1994;75(2) :803-811.

23. Stuckless N, Goranson C. The Vengeance Scale: Development of a measure of attitudes toward revenge. Journal of Social Behavior and Personality. 1992;7(1):25-42.

24. Eagly AH, Steffen VJ. Gender and aggressive behavior: A metaanalytic review of the social psychological literature. Psychol Bull. 1986;100(3):309-330.

25. John OP, Srivastava S. The Big Five trait taxonomy: History, measurement, and theoretical perspectives. In: Pervin LA, John OP (Eds.), Handbook of personality: Theory and research. (2nd edn), Guilford press, New York, USA. 1999. p.102-138.

26. Digman J, Inouye J. Futher specifications of the five robust factors of personality. Journal of Personality and Social Psychology. 1986;50(1):116-123.

27. Emmons RA. Current status of the motive concept. In: Craik KH, Hogan R, Wolfe RN (Eds.), Fifty years of personality psychology, Plenum, New York, USA. 1993. p.187-196.

28. Berkowitz. On the formation and regulation of anger and aggression: A cognitive-neoassociationistic analysis. Am Psychol. 1990;45(4):494-503.

29. Martin R, Watson D. Style of anger expression and its relation to daily experience. Personality and Social Psychology Bulletin. 1997;23(3):285-294.

30. Brown RP. Measuring individual differences in the tendency to forgive: Construct validity and links with depression. Pers Soc Psychol Bull. 2003;29(6):759-771.

31. Costa PT, McCrae RR. NEO-PI-R professional manual. Odessa, FL: Psychological Assessment Resources. 1992.

32. Wade NG, Worthington EL. Overcoming inter- personal offenses: Is forgiveness the only way to deal with unforgiveness? Journal of Counseling and Development . 1990;81(3):343-353.

33. Enright RD, Gassin EA, Wu C. Forgiveness: A developmental view. Journal of Moral Education. 1992;21(2):99-114.

34. Brose LA, Rye MS, Lutz-Zois C, et al. Forgiveness and personality traits. Personality and Individual Differences. 2005;39(1):35-46. 